\title{
Comparative Environmental and Cost Analysis of Alternative Production Scenarios Associated with a Helicopter's Canopy
}

\author{
Christos V. Katsiropoulos ${ }^{*}+\mathbb{D}$, Andreas Loukopoulos ${ }^{\dagger}$ and Spiros G. Pantelakis ${ }^{\dagger}$ \\ Laboratory of Technology \& Strength of Materials, Department of Mechanical Engineering \& Aeronautics, \\ University of Patras, Panepistimioupolis Rion, 26500 Patras, Greece; andreasloukopoulos@upnet.gr (A.L.); \\ pantelak@mech.upatras.gr (S.G.P.) \\ * Correspondence: xkatsiro@mech.upatras.gr; Tel.: +30-261-096-9498 \\ † These authors contributed equally to this work.
}

Received: 9 November 2018; Accepted: 28 December 2018; Published: 3 January 2019

\begin{abstract}
In the present work the carbon footprint and the financial viability of different materials, manufacturing scenarios, as well as recycling scenarios, associated with the production of aeronautical structural components are assessed. The materials considered were carbon fiber reinforced epoxy and carbon fiber reinforced PEEK (polyetheretherketone). The manufacturing techniques compared were the autoclave, resin transfer molding (RTM) and cold diaphragm forming (CDF). The recycling scenarios included mechanical recycling and pyrolysis. For this purpose, Life Cycle Analysis (LCA) and Life Cycle Costing (LCC) models were developed and implemented for the case of a helicopter's canopy production. The results of the study pointed out that producing the canopy by using carbon fiber reinforced thermosetting composites and involving RTM as the manufacturing process is the optimal route both in terms of environmental and financial efficiency. The environmental and financial efficiency of the scenarios including thermoplastic composites as the material of choice is impaired from both the high embodied energy and raw material cost of PEEK. The scenarios investigated do not account for potential benefits arising from the recyclability and the improved reusability of thermoplastic matrices as compared to thermosetting ones. This underlines the need for a holistic aircraft structural optimization approach including not only performance and weight but also cost and environmental criteria.
\end{abstract}

Keywords: life cycle analysis; cost analysis; autoclave; resin transfer molding; cold diaphragm forming; composite materials; aeronautic component

\section{Introduction}

Carbon fiber reinforced polymer composites have been widely adopted from the aeronautical industry (e.g., 52\% in Airbus A350, 50\% in Boeing B787 etc.) in primary as well as secondary structures, as well as in many other similar lightweight structures, which leads to decreased fuel consumption. On the other hand, it is worth mentioning that the selection process of the appropriate material for an aircraft structural application is a vital step, made at the early design stages, and has to fulfill a number of currently applied structural optimization criteria (weight reduction, cost minimization, efficient mechanical properties, etc.). In parallel, environmental considerations should, nowadays, represent a significant parameter both for selecting a material, as well as for designing an aircraft's structure and manufacturing it.

The mainstream composite material type for aeronautical applications is thermosetting composites, mainly carbon fiber reinforced epoxies, because of their low processing temperatures, low viscosity, 
superior adhesion to fibers, fatigue strength, etc. However, issues associated with their long curing cycles which lead to low production rates combined with growing environmental concerns associated with their end-of-life treatment, as well as the adoption of stricter environmental policies, have turned the attention of the aeronautical industry to alternative solutions.

On the other hand, thermoplastic composites have the ability to melt under heat and harden after cooling creating a new shape. This process can be repeated multiple times. This characteristic offers possibilities for adopting faster composite processing techniques with reduced processing time. Moreover, thermoplastic composites exhibit superior impact and chemical resistance, unlimited shelf-life, and the ability to assemble sub-structures by welding, which leads to weight reduction and recyclability; properties that thermosetting composites are unable to provide. On the downside, the higher processing temperatures and pressures needed for processing these materials, which leads to both increased energy consumption and tooling cost, are key barriers for their wide-scale use for the construction of primary structures by the aeronautical industry. Additionally, the severe deterioration of the mechanical properties of the materials during the recycling process poses a burden for exploiting their recyclability.

As far as the manufacturing techniques are concerned, out of autoclave techniques demonstrate high potential for significant financial and environmental benefits as compared to the conventional autoclave process, although autoclaving is expected to lead to higher product quality. However, concerning the recycling processes, the recyclability of the material is still defined on the basis of commonly used recycling methods, including pyrolysis and landfill, which might exhibit lower energy demands. However, they lead to products with a low or without reusability potential. These conflicting parameters underline the necessity for developing tools and concepts allowing the simultaneous optimization of a product with regard to quality, cost and environmental impact.

The available works on this topic are few and limited to either the environmental footprint or the cost quantification of a product. In this context, several studies have performed either Life Cycle Analysis (LCA) of carbon fiber reinforced polymers, e.g., [1-7] or Life Cycle Costing (LCC) analysis, e.g., References [8-11] of carbon fiber reinforced polymers. An LCA study was conducted by Timmis et al. [1] to quantify the environmental impact derived from the use of composite materials in an aircraft's fuselage used in place of other structural materials (e.g., aluminum alloys). The results highlighted that the overall environmental impact which occurred from the adoption of composite materials is positive compared with traditional materials (e.g., aluminum). In Reference [2] an overview of currently used composite materials for aviation, as well as possible bio-based and recycled substitution materials, with the focus on their ecological properties is presented. Apart from conventional materials, several types of novel materials were considered to reduce ecological impacts compared to the state-of-the-art, such as bio-based thermoset resins (epoxy, furan), bio-based fibers (flax, ramie) and recycled carbon fibers. Moreover, Duflou et al. [3] and Song et al. [4] quantified the environmental footprint of composites when they replaced steel, which is of limited use in aircraft structural applications (e.g., $7 \%$ in A350), but of great importance in automotive applications. Both latter studies demonstrated that composite materials outperformed steel due to the weight savings that they offer during the in-use phase.

Furthermore, a number of studies are dedicated to the cost efficiency assessment of the composite materials, e.g., References [8-11]. In Reference [8], an overview of the extensive field of cost estimation for aerospace composite production, describing the basic methods of how to perform cost estimation and introducing some of the existing LCC models, is made. In addition, in Reference [10], an LCC procedure is developed using cost equations to accurately estimate the recurring cost to manufacture of an aircraft control surface (leading edge flap) applicable to resin transfer molding (RTM) and vacuum-assisted resin transfer molding (VARTM). A novel concept for the optimization of manufacturing processes of composite material components with regard to product's quality and cost is introduced in Reference [11] and applied for the case of thermoplastic composite helicopter canopies produced by 'cold' diaphragm forming (CDF) process. 
On the other hand, a limited number of existing works refer to combined LCA and LCC analyses [12-20]; the few available works are rarely related to composites. In Reference [13] the application of an LCA/LCC integrated model is described for the comparison of an AGL (Anti-Glare Lamellae) currently manufactured from virgin HDPE (High Density PolyEthylene) with an alternative one made with recycled HDPE. The obtained results show that neither the current nor the new AGL depict the best environmental performance in all impact categories. Nevertheless, a clear overall environmental and economic advantage in replacing virgin HDPE with recycled HDPE was exhibited. Reference [14] combines LCC and LCA in the case of a residential district energy system area in Finland aiming to identify the actual technologies that could provide the highest sustainable viability and assesses the emissions and relative mitigation potentials associated with the different technologies. Furthermore, in Reference [17] an LCA study, as well as an LCC analysis, were carried out for a refractory brick production company, and in Reference [18] the evaluation of the process-based cost and environmental footprint profile of green composite under a twofold assessment is considered.

In Reference [20] a combined environmental and cost assessment dedicated to composite materials is performed. However, it is on an automotive application (steel vehicle bulkhead). In this study, the economic and environmental effects of substituting steel for lighter weight alternatives with the focus on composite materials was presented; thus, four material scenarios, as well as automated preforming technology, combined with reaction injection molding were chosen. Manufacturing and life-cycle costs were derived from a technical cost model, and the environmental performance of each scenario was then quantified using LCA according to ISO guidelines. Therefore, there is not any available work in the open literature, combining the comparison of a number of processes used in aeronautics with regards both to LCA and LCC studies for a composite aeronautic product, either thermoplastic or thermoset.

This work aims to make a comparative analysis in terms of carbon emissions and financial efficiency for different material, manufacturing, and recycling scenarios associated with the production of an aeronautical structural component; the canopy of the EUROCOPTER EC Twin Star helicopter described in Reference [11], Figure 1. In addition, the present work introduces a new holistic approach which accounts for not only cost and environmental footprint but also for additional features, such as the quality of the product as well as reusability and recyclability aspects. In such an approach, these features would be taken into account at the design phase of a product.

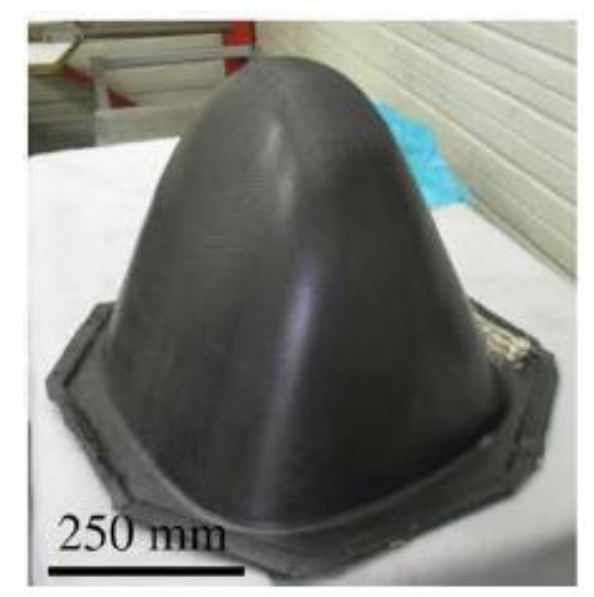

Figure 1. The canopy described in Refference [4] (1:3 scale prototype of the real part).

\section{Methods}

\subsection{Life Cycle Analysis}

Life cycle analysis is a standardized technique (ISO 140402006 [21]) for assessing the environmental performance of a product or a process at various points in their life cycle, from raw material extraction 
to disposal or recycling. The stages for carrying out a Life Cycle Analysis are the following: Goal and scope definition, inventory analysis, impact assessment, and interpretation of the results.

Based on this concept, an LCA model was developed for evaluating the environmental footprint in terms of carbon emissions of the canopy of the Twin Star Helicopter, which is the case study under investigation, acting as the functional unit of the system. The stages taken into consideration for the present LCA were: carbon fiber production, epoxy (TS) and PEEK (PolyEtherEtherKetone)-(TP) production, manufacturing (autoclave, resin transfer molding (RTM), cold diaphragm forming (CDF)) and recycling (mechanical recycling and pyrolysis).

Epoxy resins are the most commonly used matrix material for composite material aircraft structural applications. In this context, toughened epoxies have found widespread application. However, their use in high-performance applications is limited by low service temperature that is adversely affected by moisture content, loading, and by the use of toughening agents. In general, the maximum use temperature for advanced epoxies is limited to $150^{\circ} \mathrm{C}$ to $180^{\circ} \mathrm{C}$. Other disadvantages include brittleness and moisture absorption that can lower use temperature as mentioned above. However, epoxy resins provide many attractive features, including good handling properties, processability, and low cost.

On the other hand, PEEK (PolyEtherEtherKetone) is commonly used for the matrix of TP prepregs containing mainly carbon fibers and is selected as the most prevalent TP resin used in aeronautics. PEEK has been reported to be capable of withstanding continuous operating temperature up to $260{ }^{\circ} \mathrm{C}$ in low-stress operations and $120^{\circ} \mathrm{C}$ in aerospace structural applications. Moreover, PEEK has good resistance to hydrolysis, corrosion, chemical, and radiation exposure. It provides high thermal stability, a low coefficient of expansion, good abrasion resistance, low smoke and toxic gas emission, and excellent stiffness. Last, but not least, an essential advantage is recyclability which, however, requires high energy consumption.

In the present work, a Bisphenol-A epoxy-based vinyl ester resin was selected as the TS representative of toughened epoxies and PolyEtherEtherKetone (PEEK) resin as a TP competitor, both reinforced with carbon fibers. These systems were chosen to compare the environmental impact and cost of a commonly used non-recyclable material (epoxy composite) with a recyclable material (PEEK composite).

In regard to the processes under investigation, autoclave and RTM, as a representative of autoclave processes, were selected as they are the most commonly used processes to produce structural aeronautical components. They are capable of producing parts of acceptable quality according to the aeronautics standards. Cold diaphragm forming (CDF), has a low cost and seems to be promising for aeronautical applications. Therefore, the above mentioned three processes were selected for our investigation. CDF was considered only for the thermoplastic composite, as it cannot be used to process thermosetting matrices, whereas autoclave and RTM can be used for both. Moreover, pyrolysis was considered only for the scenarios involving thermosetting composite as the material of choice whereas mechanical recycling was considered for both thermoplastic and thermosetting composites. The processes under investigation were assumed to be all electric.

For each stage, the total energy demands, as well as the Global Warming Potential-100 (GWP $\left.{ }_{100}\right)$ for a period of 100 years, were estimated. $\mathrm{GWP}_{100}$ was selected as the most critical environmental impact category commonly used among LCA studies for evaluating the carbon footprint and is suitable for this study as electricity generation produces mainly $\mathrm{CO}_{2}$ emissions. The system boundaries are shown in Figure 2. The total energy consumption was calculated by multiplying the mass of each material with the energy intensity of each process (Equation (1)), which was derived from literature $[5,22-25]$ and is shown in Table 1 . Since the processing temperature of PEEK is almost three times higher than the processing temperature of epoxy, the energy demands at the manufacturing stage were assumed to be three times higher as well. The $\mathrm{GWP}_{100}$ was calculated by multiplying the $m_{\mathrm{CO} 2 \mathrm{eq}}$, which is the mass of $\mathrm{CO}_{2}$ emission that is produced from the consumption of $1 \mathrm{kWh}$ of 
electricity, with the total energy demands of each process (Equation (2)). The $m_{\mathrm{CO} 2 \mathrm{eq}}$ was considered equal to $0.34 \mathrm{~kg} \mathrm{CO}_{2 \mathrm{eq}} / \mathrm{kWh}[26]$.

$$
\begin{aligned}
E_{i} & =m_{i} e_{i} \\
G W P_{100} & =E_{i} \frac{m_{\mathrm{CO}_{2} \mathrm{eq}}}{\mathrm{kWh}}
\end{aligned}
$$

where $E_{i}$ is the total energy of each process in $\mathrm{kWh}, m_{i}$ is the total mass in $\mathrm{kg}$ of each material involved, $e_{i}$ is the energy intensity for each process in $\mathrm{kWh} / \mathrm{kg}, \mathrm{GWP}_{100}$ is the Global Warming Potential for a period of 100 years in $\mathrm{kg}, m_{\mathrm{CO} 2 \mathrm{eq}}$ is the mass in $\mathrm{kg}$ of $\mathrm{CO}_{2}$ emission that is produced from the consumption of $1 \mathrm{kWh}$ of electricity.

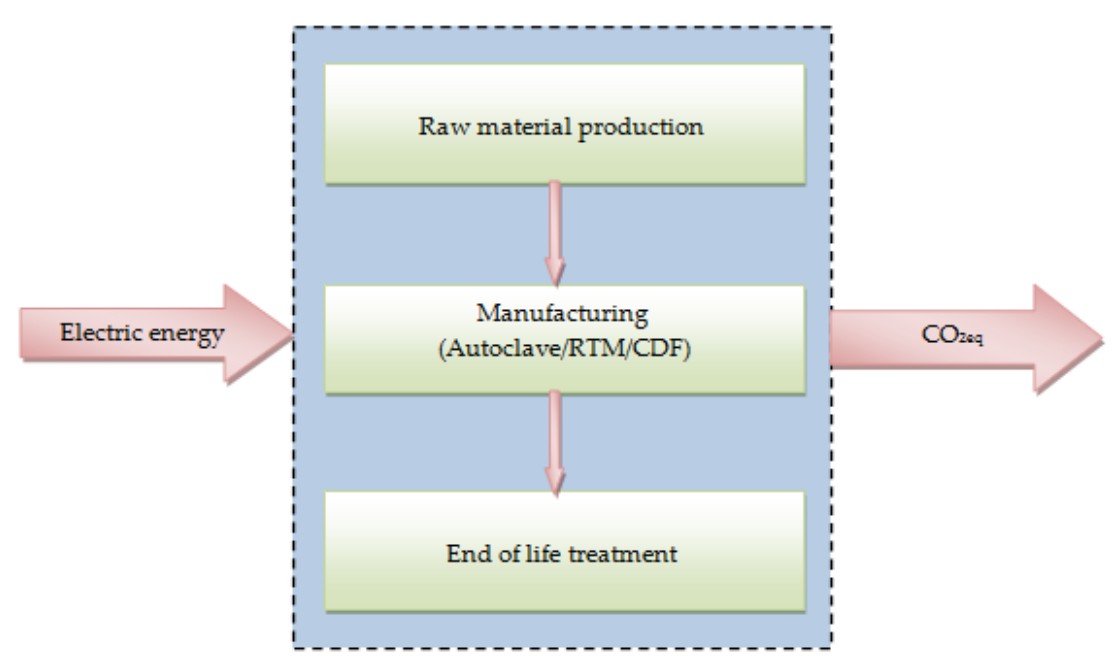

Figure 2. System boundaries.

Table 1. Energy intensity of each process.

\begin{tabular}{cc}
\hline Process & Energy Intensity $(\mathbf{k W h} / \mathbf{k g})$ \\
\hline Carbon fiber production & $155[22]$ \\
Epoxy production & $21.11[5,23]$ \\
PEEK production & $77.78[24]$ \\
Autoclave TS & $4.97[22]$ \\
Autoclave TP & 14.9 \\
RTM TS & $2.86[22]$ \\
RTM TP & 8.58 \\
CDF & $9[11]$ \\
Mechanical recycling & $0.075[25]$ \\
Pyrolysis & $6.67[26]$ \\
\hline
\end{tabular}

\subsection{Life Cycle Costing}

The Life Cycle Cost analysis is a suitable tool for determining financial trade-offs arising from a product or a process. In this study, an LCC model was developed based on the principles of the Activity Based Costing method ( $\mathrm{ABC}$ ). $\mathrm{ABC}$ is an accounting method implementing cost estimation mathematical relationships (CERs) for expressing the cost as a function of one or more independent variables that take into account the geometrical features of a material or a product, such as the perimeter (PAP), surface (PAA), length (L) shape complexity ( $\mathrm{cmp}$ ), and mass (WP). In the performed analysis, costs associated with labor, material, and energy were calculated. The performed cost analysis also accounts for recycling cost which was assumed equal to the energy cost of the recycling process. CERs were either formulated or adopted from Reference [11].

In the framework of the LCC analysis, the cost of $1 \mathrm{kWh}$ was considered equal to 0.114 Euros [27] and the labor cost $\left(k_{w}\right)$ equal to 32.6 Euros/hour [27]. The cost of the raw material was considered 
equal to the cost of its constituents ( $K_{m f}$ is the cost of carbon fibers and $K_{m r}$ the cost of the resin). Additionally, the empirical assumption of $80 \%$ of scrap material based on Reference [4] was made for all the manufacturing processes. The energy cost for all the processes was calculated as follows, and all the CERs developed are shown in Tables 2 and 3:

$$
\begin{gathered}
K_{i}=E_{i} k_{i} \\
K_{\text {total }}=K_{\text {labor }}+K_{\text {material }}+K_{\text {energy }}+K_{\text {recycling }}
\end{gathered}
$$

where $K_{i}$ is the total energy cost, $E_{i}$ is the total energy consumption and $k_{i}$ is the cost of $1 \mathrm{kWh}$ of electricity.

In this study, non-recurring costs are not taken into account. However, an effort is made to evaluate the equipment cost of autoclaving and RTM based on data available from a company specializing in online commerce (www.alibaba.com).

Table 2. Labor cost.

\begin{tabular}{cc}
\hline Activity & CER $[11,28]$ \\
\hline Clean the mold & $K_{c m}=k_{w}{ }^{*} 1^{*} 2^{*} \mathrm{PAA}$ \\
Application of the release agent & $K_{r a}=k_{w}^{*} 0.1^{*} \mathrm{PAA}$ \\
Cut prepreg (10 plies) & $K_{c u}=k_{w}{ }^{*} 0.25^{*} \mathrm{PAP}$ \\
Cut diaphragms & $K_{d}=1.6 k_{d}^{*} \mathrm{PPA}^{*} N_{D}$ \\
Lay up & $K_{\text {layup }}=k_{w}{ }^{*} t_{l a y u p} 8$ min. for the first 2,4 min. for the rest \\
Cut breather/bleeder/release film/sealing bag/peel plies & $K_{p l}=k_{w}^{*} 0,25^{*} \mathrm{PAP}$ \\
Demolding & $K_{d e}=k_{w}{ }^{*} 0.25^{*} \mathrm{PAA}$ \\
Cost of the rework & $K_{r w w}=k_{w}^{*} 0.25^{*} \mathrm{PAP}$ \\
Cost of the NDT inpection & $K_{i n s}=k_{w}^{*}\left(1^{*} \mathrm{PAA}{ }^{*} \mathrm{cmp}+0.5\right)$ \\
Cost of the dimension measurement & $K_{d i m}=k_{w}^{*} 0.5^{*} \mathrm{cmp}{ }^{*} \mathrm{PAA}$ \\
Cost of the storage & $K_{s t}=k_{w}^{*}\left(0.05^{*} \mathrm{WP}+0.16^{*} \mathrm{PAP}\right)$ \\
\hline
\end{tabular}

Table 3. Material cost.

\begin{tabular}{cc}
\hline Material & CER \\
\hline Cleaning agent & $K_{c m}=k_{c m}{ }^{*} \mathrm{PAA}^{*} m_{c m}{ }^{*} 2[11]$ \\
Release agent & $K_{r a}=k_{r a}{ }^{*} \mathrm{PAA} /$ Coverage \\
Breather/bleeder/release film/peel ply, sealing bag, diaphragms & $K_{i}=k_{i}^{*} L_{i}$ \\
Raw material & $K_{\text {total }}=1.8^{*}\left(K_{m f}+K_{m r}\right)=1.8^{*} k_{m f}^{*} m_{m f}+1.8^{*} k_{m r}{ }^{*} m_{m r}$ \\
\hline
\end{tabular}

\section{Results and Discussion}

\subsection{Life Cycle Analysis}

The results from the Life Cycle Analysis demonstrated that the production of carbon fiber is responsible for more than $80 \%$ of the total carbon footprint (Figure 3 ). These findings highlight the need for developing new or improve the existing recycling techniques to avoid the production of new carbon fibers. Figures 4 and 5 demonstrate that producing the canopy using a carbon fiber reinforced epoxy composite, involving RTM as the manufacturing process and mechanical recycling as the end-of-life treatment route demonstrates the lowest carbon footprint. On the contrary, the worst practice for producing the canopy is when a carbon fiber reinforced thermoplastic composite is the material of choice, and autoclaving is the manufacturing process selected because of the high embodied energy and processing temperature of PEEK as well as the higher energy demands of the autoclave equipment. The environmental performance of producing a thermoplastic canopy is improved when out of autoclave techniques (RTM and CDF) are considered as the manufacturing processes, but this amelioration is not enough to provide a lower life-cycle carbon impact. 


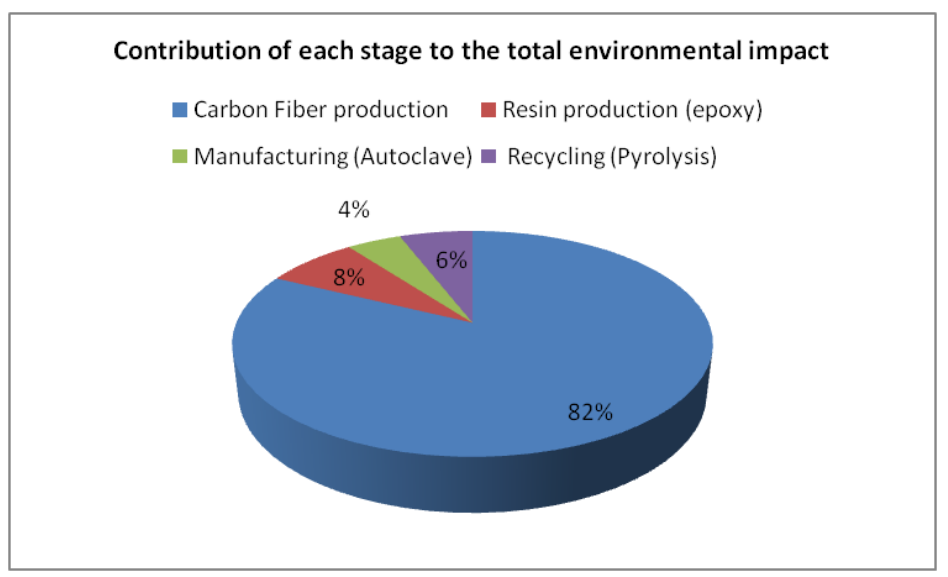

Figure 3. Contribution of each stage to the total environmental impact.
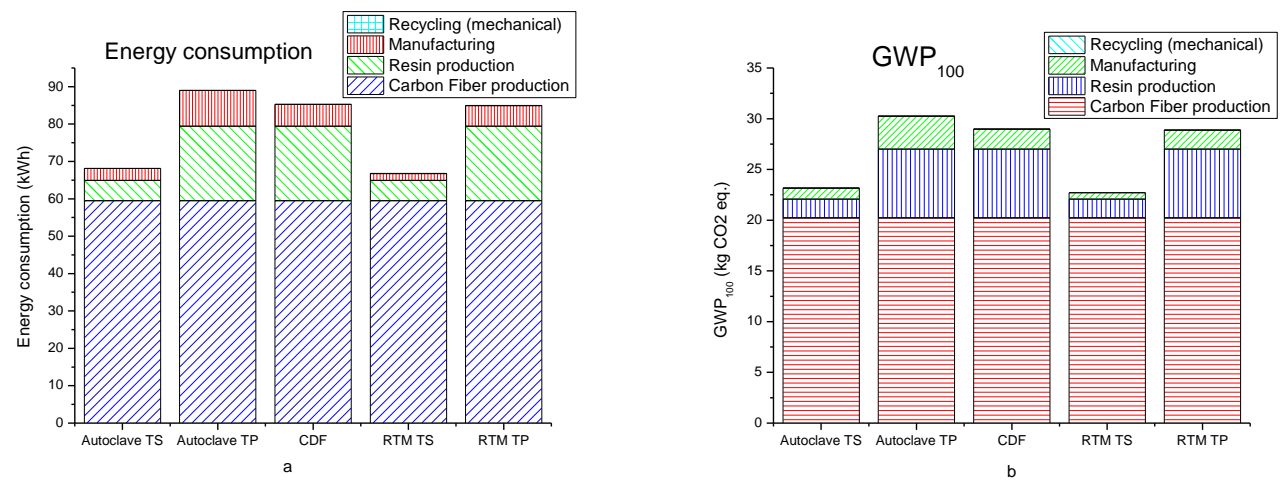

Figure 4. (a) Total energy consumption and (b) Global Warming Potential-100 for each process scenario when mechanical recycling is considered.
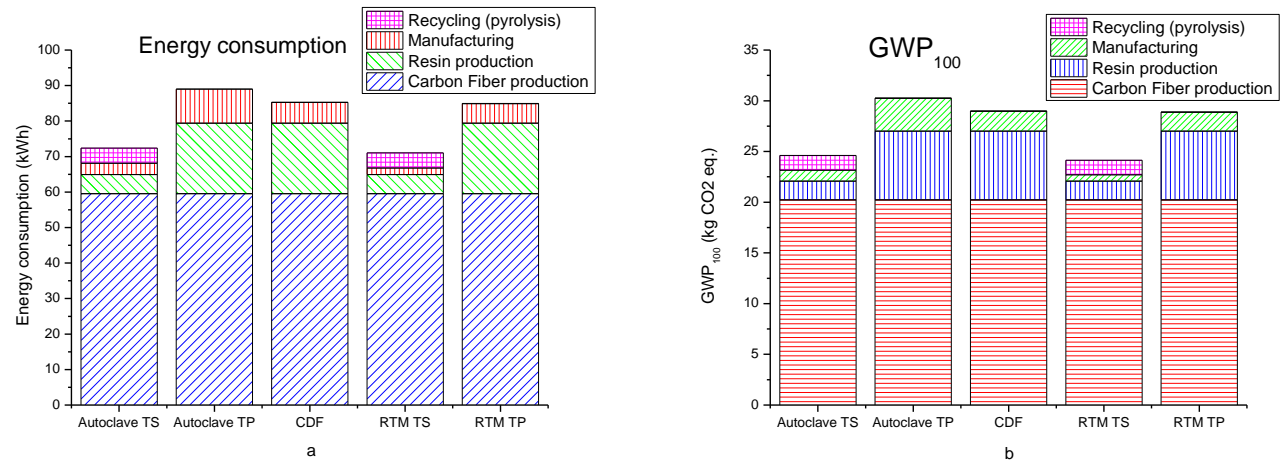

Figure 5. (a) Total energy consumption and (b) Global Warming Potential-100 for each process scenario when mechanical recycling is considered for thermoplastic and pyrolysis for thermosetting composite.

However, as already mentioned, the present study is limited to the investigation of the carbon impact without accounting for recyclability and reusability of the composite material. Therefore, it results in the paradoxical conclusion that a non-recyclable material (epoxy composite) is a more environmentally friendly alternative (lower carbon footprint) as compared to a recyclable material (PEEK composite). It should be noticed that landfill (disposing waste material by burial) is a relatively cheap disposal route and mostly used in overseas countries (e.g., USA) but is the least preferred waste management option under the European Union's Waste Framework Directive, and, therefore, opposition to it is expected to increase over the coming years. This route is already not permitted in Germany, while other EU countries are expected to follow.

It is worth noting that recycling techniques studied and implemented during the last two decades in Europe, such as mechanical processes (mainly grinding), pyrolysis, solvolysis, and other thermal 
processes, are not satisfactory as they either downgrade the quality of the recycled material appreciably (e.g., grinding) or are associated with enormous energy consumption (e.g., pyrolysis). To assess the efficiency of a recycling process, more holistic evaluation criteria would be needed to account for energy consumption, overall environmental impact including carbon footprint, and reusability, as well as the quality of the recycled material.

\subsection{Life Cycle Costing}

Figure 6 reveals that material and labor costs are responsible for $19 \%$ and $81 \%$ of the total cost, respectively. Energy and recycling costs are negligible when compared with material and labor cost. For this reason, in the following, only scenarios where mechanical recycling is considered as the recycling technique are shown. Moreover, from Figure 7, it is obvious that producing the canopy from carbon fiber reinforced epoxy composite using the RTM technique is the best option from a financial standpoint. This is the result of the lower raw material cost of the epoxy composite as compared to thermoplastic and of the absence of auxiliary materials (breather films, vacuum bags, diaphragms, etc.) for the RTM process. Furthermore, the fewer steps needed for preparing the mold decreases the labor cost of RTM by $35 \%$ and by $26 \%$ as compared to the conventional autoclave technique and CDF, respectively (Figure 8). The financial performance of the scenarios involving PEEK composite is impaired from the high raw material cost. However, it can be expected that the financial performance of the thermoplastic composites will be appreciably improved when the higher production rates offered from these materials are considered as a decision-making parameter. In addition, their high reusability potential can be taken into account.

Figure 9 demonstrates a characteristic example of the effect of the main cost drivers to the total cost of an activity. It exhibits the cost variation for storing the component as a function of two product's features, the weight and the perimeter, revealing that this activity is more sensitive to a perimeter increase than to a weight increase.

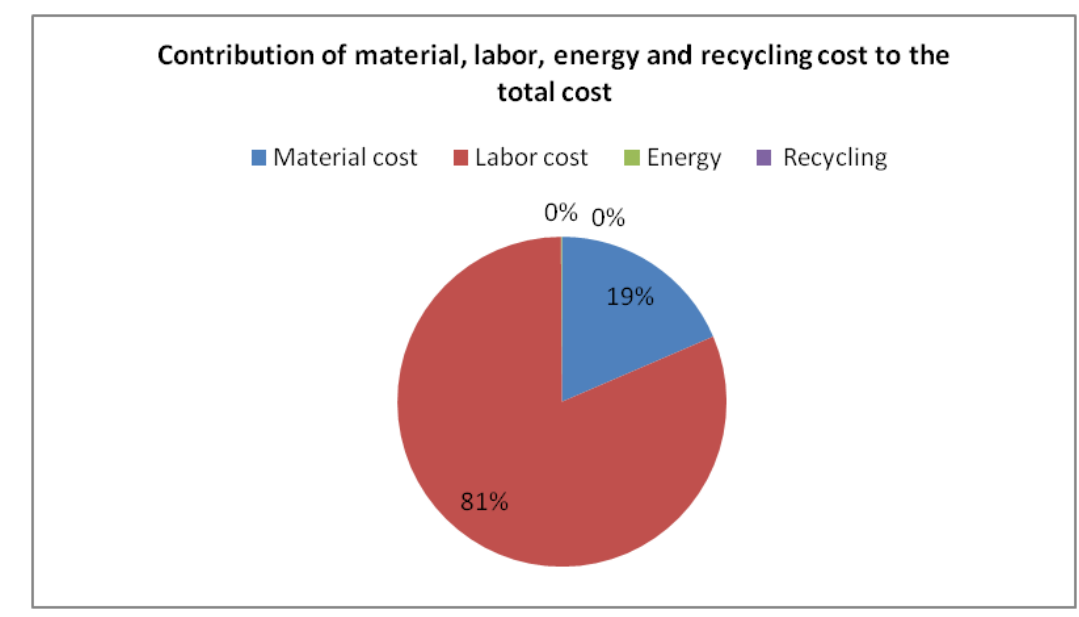

Figure 6. Contribution of the material, labor, energy and recycling cost to the total cost (autoclave-thermosetting composite). 


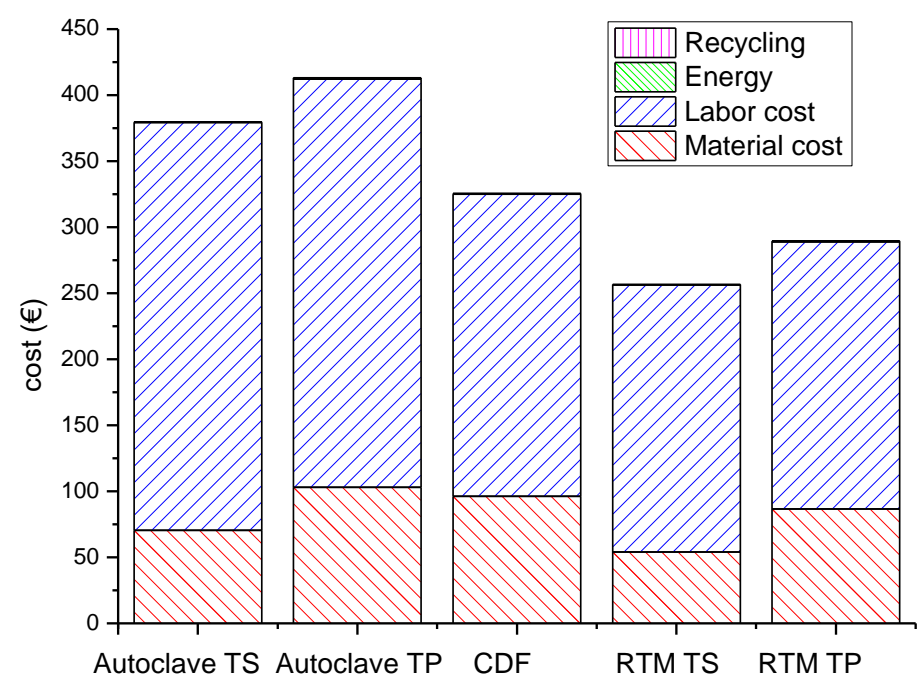

Figure 7. Total cost for the different manufacturing scenarios examined.
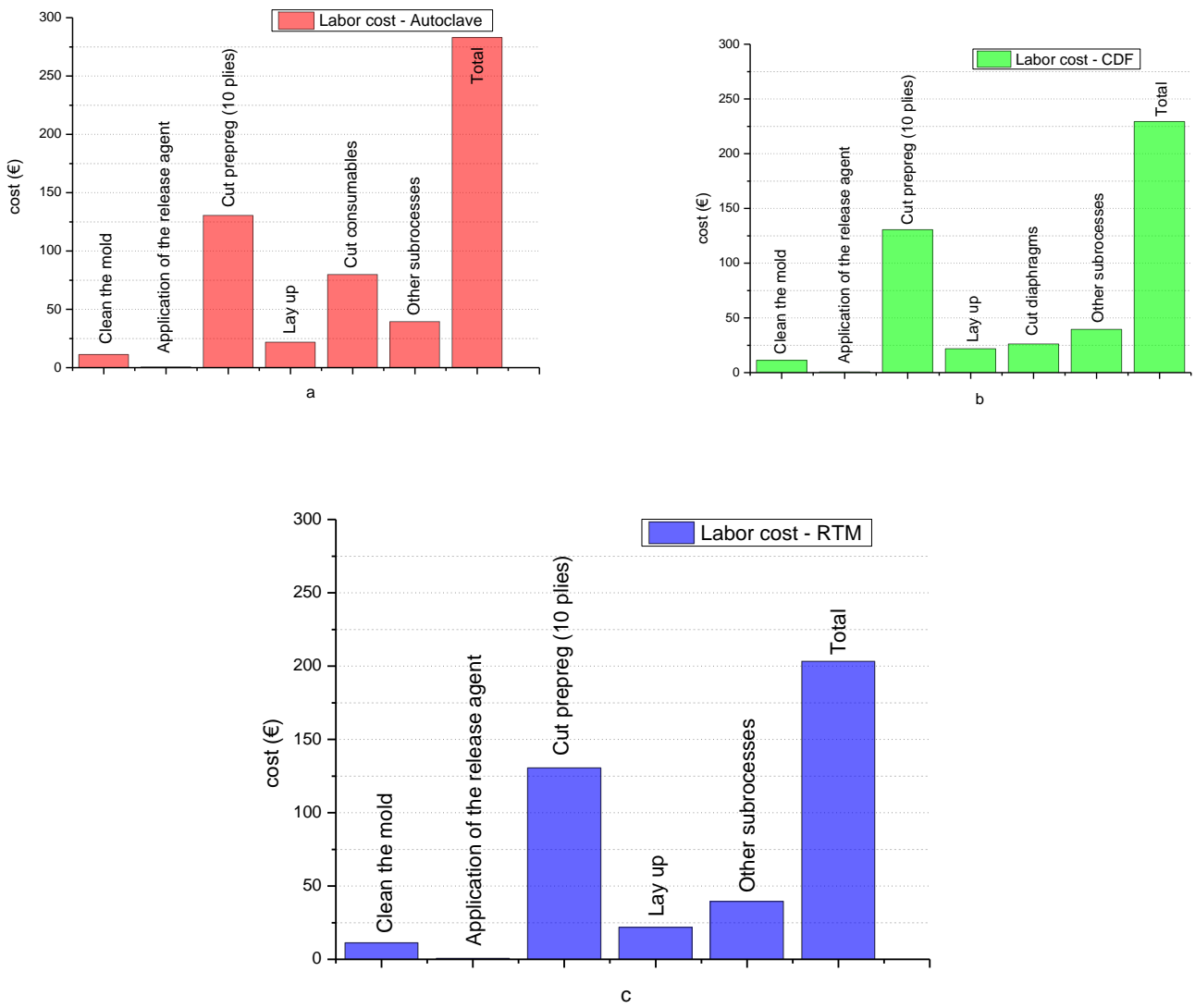

Figure 8. Labor cost breakdown structure for (a) Autoclave, (b) CDF, (c) RTM. 


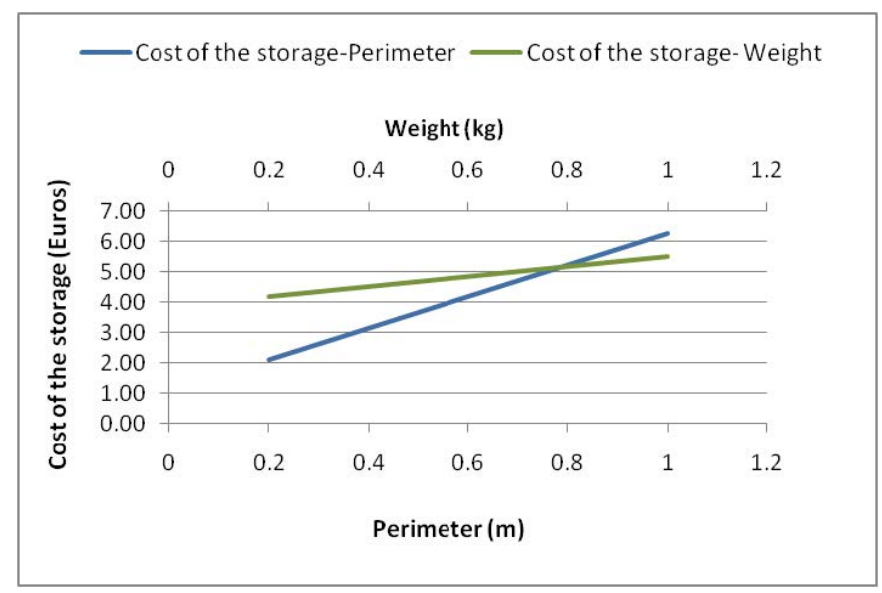

Figure 9. Cost of the storage as a function of the perimeter and of the weight.

As far as the investment cost for the manufacturing processes is concerned, this is strongly dependent on the size of the equipment, maximum working temperature and pressure as well as heating and cooling rates, injection capacity (for RTM) etc. In this frame, a cost evaluation of an autoclave and RTM (injection/mixing machine) equipment was made and is shown in Figure 10. From this figure, it is obvious that the investment cost of autoclaving is more than three times higher compared with RTM. On the other hand, increased cost of the molds used in RTM, as well as additional costs related with the design of the mold (e.g., for defining the injection line), and not taken into account in this study, impair the financial performance of RTM.

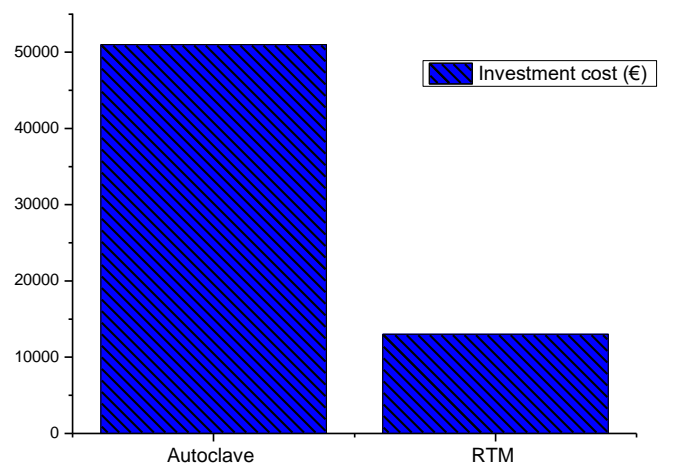

Figure 10. Investment cost of autoclaving and RTM.

\section{Conclusions}

In the present work a Life Cycle Analysis (LCA) combined with a Life Cycle Cost (LCC) analysis was carried out to estimate the carbon footprint and financial efficiency of different material, manufacturing, and end-of-life scenarios associated with the production of an aeronautical composite structure: the canopy of the Twin Star helicopter. The results from the environmental analysis demonstrated that the embodied energy of the raw materials and the energy intensity of each process are the key factors affecting the carbon footprint, and are the cause of the lower ecological performance of PEEK composite compared with thermosetting epoxy composite. As far as the cost analysis is concerned, the main cost drivers are the cost of the materials (raw and auxiliary materials) and the cost for preparing the mold for the process.

However, parameters not taken into account in this study, such as higher product quality referring to increased mechanical properties and lack of defects provided by autoclaving; higher productivity offered by thermoplastic composites due to reduced processing cycles; assembling potential, such as the use of welding that is expected to lead to lower assembling costs and weight reduction, as well as recyclability can affect the decision strategy at the early design stages. This also underlines the need 
for a holistic approach to include potential reuse and 'clear' recycling applications of the composites, as well as circular economy considerations when establishing the criteria for designing an aircraft structure, selecting the material and finally manufacturing the structure.

Finally, this analysis makes evident the need for developing a versatile concept able to both deal with intricate tasks and provide the optimal design options among different alternatives.

Author Contributions: C.V.K. was involved in the conceptualization as well as in the project administration/ supervision and the review/editing of the manuscript. A.L. performed the formal analysis, the data investigation, the writing a big part of the original manuscript and the application of the methodology. S.G.P. supervised and validated the project as well as contributed to the final editing and review of the manuscript.

Funding: The present work was partially funded from EU NHYTE project.

Acknowledgments: The present work is a preliminary study performed within NHYTE project (NHYTE, 2017-2020). The NHYTE project has received funding from the European Union's Horizon 2020 research and innovation programme under grant agreement No. 723309 .

Conflicts of Interest: The authors declare no conflict of interest.

\section{References}

1. Timmis, A.J.; Hodzic, A.; Koh, L.; Bonner, M.; Soutis, C.; Shafer, A.W.; Dray, L. Environmental impact assessment of aviation emission reduction through the implementation of composite materials. Int. J. Life Cycle Assess. 2015, 20, 233-243. [CrossRef]

2. Bachman, J.; Hidalgo, C.; Bricout, S. Environmental analysis of innovative sustainable composites with potential use in aviation sector-A life cycle assessment review. Sci. China Technol. Sci. 2017, 60, 1301-1317. [CrossRef]

3. Duflou, J.R.; Deng, Y.; Van Acker, K.; Dewulf, W. Do fiber-reinforced polymer composites provide environmentally benign alternatives? A life-cycle-assessment-based study. MRS Bull. 2012, 37, 374-382. [CrossRef]

4. Song, Y.S.; Youn, J.R.; Gutowski, T.G. Life cycle energy analysis of fiber-reinforced composites. Compos. Part A 2009, 40, 1257-1265. [CrossRef]

5. Michaud, V. Les Matériaux Composites, Moteurs de la Mobilité Proper. Presented at the Swiss Mobility Days, Martigny, Switzerland, 7 April 2016.

6. Deng, Y. Life Cycle Assessment of Biobased Fibre-Reinforced Polymer Composites. Ph.D. Thesis, Katholieke Universiteit Leuven, Leuven, Belgium, 2014.

7. Das, S. Life cycle assessment of carbon fiber-reinforced polymer composites. Int. J. Life Cycle Assess. 2011, 16, 268-282. [CrossRef]

8. Hueber, C.; Horejsi, K.; Schledjewski, R. Review of cost estimation: Methods and models for aerospace composite manufacturing. Adv. Manuf. Poly. Compos. Sci. 2016, 2, 1-13. [CrossRef]

9. Bader, M.G. Selection of composite materials and manufacturing routes for cost effective performance. Compos. Part A 2002, 33, 913-934. [CrossRef]

10. Barlow, D.; Howe, C.; Clayton, G.; Brouwer, S. Preliminary study on cost optimization of aircraft composite structures applicable to liquid moulding technologies. Compos. Struct. 2002, 57, 53-57. [CrossRef]

11. Pantelakis, S.G.; Katsiropoulos, C.V.; Labeas, G.N.; Sibois, H. A concept to optimize quality and cost in thermoplastic composite components applied to the production of helicopter canopies. Compos. Part A 2009, 40, 595-606. [CrossRef]

12. Soares, S.R.; Finotti, A.R.; da Silva, V.P.; Alvarenga, R.A. Applications of life cycle assessment and cost analysis in health care waste management. Waste Manag. 2013, 33, 175-183. [CrossRef] [PubMed]

13. Simões Carla, L.; Costa Pinto Lígia, M.; Bernardo, C.A. Environmental and economic assessment of a road safety product made with virgin and recycled HDPE: A comparative study. J. Environ. Manag. 2013, 114, 209-215. [CrossRef] [PubMed]

14. Miro, R.; Antti, S.; Jukka, H.; Seppo, J. Combining life cycle costing and life cycle assessment for an analysis of a new residential district energy system design. Energy 2013, 63, 168-179. 
15. Antonella, P.; Fabio, D.; Elio, J.; Claudio, A.; Mariagiovanna, M.; Lavadera, L.A. Life cycle assessment (LCA) and life cycle cost (LCC) analysis model for a stand-alone hybrid renewable energy system. Renew. Energy 2016, 95, 337-355.

16. Norris, G.A. Integrating Life Cycle Cost Analysis and LCA. Int. J. LCA 2001, 6, 118-120.

17. Aysun, Ö.; Zerrin, G.; Gülden, T.; Levent, K.; Melike, M.; Müfide, B.; Alpagut, K. Life Cycle Assessment and Life Cycle Cost Analysis of Magnesia Spinel Brick Production. Sustainability 2016, 8, 662.

18. Koronis, G.; Silva, A. Green Composites Reinforced with Plant-Based Fabrics: Cost and Eco-Impact Assessment. J. Compos. Sci. 2018, 2, 8. [CrossRef]

19. Xiang, L.; Ruibin, B.; Jon, M. Environmental and financial performance of mechanical recycling of carbon fibre reinforced polymers and comparison with conventional disposal routes. J. Clean. Prod. 2016, 127, 451-460.

20. Robert, A.W.; Jırtme, P.; Veronique, M.; Christian, L.; Jan-Anders, E.M. Assessing the life cycle costs and environmental performance of lightweight materials in automobile applications. Compos. Part A 2011, 42, 1694-1709.

21. ISO 14040. Environmental Management-Life Cycle Assessment-Principles; ISO: Geneva, Switzerland, 2006.

22. Energetics Incorporated. Bandwidth Study on Energy Use and Potential Energy Saving Opportunities in the Manufacturing of Lightweight Materials: Carbon Fiber Reinforced Polymer Composites; U.S. Department of Energy: Washington, DC, USA, 2016.

23. Suzuki, T.; Takahashi, J. Prediction of energy intensity of carbon fiber reinforced plastics for mass-produced passenger car. In Proceedings of the 9th International SAMPE Symposium, Tokyo, Japan, 29 November-2 December 2005.

24. Howarth, J.; Mareddy, S.S.R.; Mativenga, P.T. Energy intensity and environmental analysis of mechanical recycling of carbon fibre composite. J. Clean. Prod. 2014, 81, 46-50. [CrossRef]

25. Job, S.; Leeke, G.; Mativenga, P.T.; Oliveux, G.; Pickering, S.; Shuaib, N.A. Composites Recycling: Where Are We Now; Composites UK Ltd.: Berkhamsted, UK, 2016.

26. Oiveux, G.; Dandy, L.O.; Leeke, G.A. Current of recycling of fibre reinforced polymers: Review of technologies, reuse and resulting properties. Prog. Mater. Sci. 2015, 72, 61-99. [CrossRef]

27. Electricity Map: Live $\mathrm{CO}_{2}$ Emissions of Electricity Consumption. Available online: www.electricitymap.org (accessed on 1 September 2018).

28. Tong, R.; Hoa, S.V.; Chen, M. Cost Analysis on L-shape Composite Component Manufacturing. In Proceedings of the 18th International Conference on Composite Materials, Jeju, Korea, 21-26 August 2011. 